\title{
ARTICULO
}

Revista Derecho - Año 2 edición 3: 121 - 139

\section{LA AUTONOMÍA DEL DELITO DE LAVADO DE ACTIVOS Y EL PRINCIPIO DE IMPUTACIÓN NECESARIA}

\author{
Carlos Noé Calisaya Rojas*
}

\section{INFORMACIÓN DEL ARTICULO}

Art. Recibido: 09/02/16

Art. Aceptado: 02/06/16

Art. Publicado: 18/12/18

PALABRAS CLAVE:

Autonomía del delito

Actos de conversión

Actos de ocultamiento

Derecho de defensa

Debido proceso

Imputación necesaria

Lavado de activos

Patrimonio

Principio de legalidad

Presunción de inocencia

Tenencia

Transferencia

\section{RESUMEN}

El objeto del presente trabajo de investigación, es analizar el delito de lavado de activos, y evaluar la viabilidad de una autonomía sustancial y/o procesal del delito en mención, regulado en el decreto legislativo 1106, que en su artículo 10 prescribe: "El lavado de activos es un delito autónomo por lo que para su investigación y procesamiento no es necesario que las actividades criminales que produjeron el dinero, los bienes, efectos o ganancias, hayan sido descubiertas, se encuentren sometidas a investigación, proceso judicial o hayan sido previamente objeto de prueba o de sentencia condenatoria..."; esto en el marco del nuevo proceso penal peruano, ya que en ella se desarrolla los principios que garantizan a todo imputado sus derechos uno de los cuales es el principio de imputación necesaria consagrado en la Constitución Política del Estado, siendo una manifestación de los principios de legalidad, del derecho de defensa y debido proceso. Considerando que se apertura investigaciones por lavado de activos por el solo hecho de tener desbalance patrimonial y/o incremento patrimonial, y sin mencionar cual es el delito precedente que habría generado dichos activos; afectándose de esta forma el principio de imputación necesaria. El tipo de investigación jurídica corresponde al dogmático jurídico.

Bachiller de la Facultad de Ciencias Jurídicas y Políticas, Escuela Profesional de Derecho de la Universidad Nacional del Altiplano. 


\section{AUTONOMY OF LAUNDERING ASSETS CRIMES AND THE PRINCIPLE OF NECESSARY IMPUTATION}

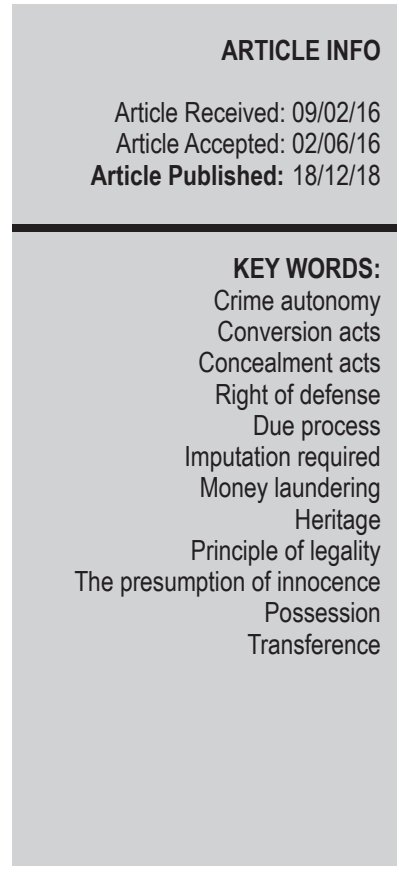

\section{ABSTRACT}

The purpose of the present research work is to analyze the crime of money laundering and to evaluate the feasibility of a substantial autonomy and/or procedural of these types of crimes in mention, regulated by legislative decree 1106 , whose article 10 stipulates: "The laundering of assets is an autonomous offense; thus, there is no need for its investigation and prosecution where criminal activities have produced money, property, effects or profits, or have been discovered or been investigated through judicial process or have previously been subject to proof or conviction..."; this in the framework of the new Peruvian penal process, where the principles that guarantee every person their rights establishes the principle of necessary imputation stated in the Political Constitution of the State, being a manifestation of the principles of legality, of the right of defense and due process. Considering the opening of investigations on laundering of assets by the mere fact of having patrimonial imbalance and/or increase, without mentioning which is the offense precedent that would have generated such assets; affecting in this way the principle of necessary imputation required. The approach of legal research corresponds to legal dogmatics. 


\section{INTRODUCCIÓN}

La presente investigación se encuentra dentro del área del Derecho Penal y Procesal Penal, en la línea investigativa de los Derechos Constitucionales del imputado dentro del marco de las distintas etapas del proceso penal, y posterior sentencia por el delito de lavado de activos regulado por el Decreto Legislativo $N^{\circ} 1106$ dado en abril del año dos mil doce.

Es evidente que en los últimos años en nuestro país, se han proliferado formas más violentas y organizadas de la delincuencia, como se observa con relación al narcotráfico, minería ilegal, trata de personas, terrorismo, etc., y que además deja de ser un problema local y/o nacional para convertirse en uno de carácter internacional o transnacional que preocupa a todos los Estados del mundo. El cual tiene una vinculación con el delito de lavado de activos que ha venido fortaleciendo a la criminalidad organizada.

El delito de lavado de activos se convierte en una amenaza, pues no solo origina gran parte de la violencia en nuestra sociedad, sino que además contamina la economía y afecta la gobernabilidad al fomentar la corrupción en nuestros funcionarios públicos. Frente a ello el Estado requiere de mecanismos y herramientas para enfrentar el lavado de activos y el crimen organizado como un grave problema.

Es en esta situación crítica que los Estados han ideado una forma para combatir los delitos de crimen organizado el cual constituye en despojar y quebrantar su sistema de financiamiento que hace posible su constitución, desenvolvimiento y permanencia dentro de la sociedad para seguir cometiendo sus actos criminales; conociendo que para el delincuente constituye una gran dificultad la utilización del producto de sus actos ilícitos esto es las ganancias; por esta razón las legislaciones del mundo han venido tipificando como delito al lavado de activos. Con la necesidad de sancionar a quienes, sin haber participado en el hecho punible "delito precedente o delito fuente", prestan ayuda eficaz a los responsables de la delincuencia obstruyendo la persecución penal "ius puniendi", de esta manera el legislador se vio en la necesidad de tipificar el lavado de activos como supuesto delito autónomo en nuestro país.

El Ministerio Público como titular del ejercicio de la acción penal conduce desde su inicio la investigación del delito con objetividad, indagando las circunstancias que permitan comprobar la imputación debiendo obtener suficientes y graves elementos de convicción con la finalidad de garantizar la mayor eficacia en la lucha contra el delito y garantizando a la vez todos los Derechos Fundamentales que la Constitución Política del Estado ampara al imputado. En el desarrollo de la investigación el Fiscal formulará sus disposiciones, requerimientos $\mathrm{y}$ conclusiones en forma motivada y específica.

En el marco de un Proceso la Constitución Política del Estado consagra un conjunto de Principios que 
rige el Proceso Penal, uno de los cuales es el Principio de Imputación Necesaria llamado también Principio de Imputación Concreta, esta no se encuentra taxativamente señalado en Carta Magna si no que se deduce a través de la interpretación del artículo $2^{\circ}$ inciso 24 parágrafo $\mathrm{d}$ y $139^{\circ}$ inciso 14 , pues este Principio de Imputación Necesaria es una manifestación del Principio de Legalidad, Principio del Derecho de Defensa y Debido Proceso.

Sin embargo, hoy en día existen dudas si en nuestro ordenamiento jurídico se custodia debidamente el Principio de Imputación necesaria y el Principio de Presunción de Inocencia en el marco del Proceso Penal, respecto a su vulneración en las Disposiciones y Requerimientos Fiscales, Pues venimos siendo testigos, para quienes somos espectadores, de su afectación y de la pobre exigencia de su tutela en el proceso penal. $\mathrm{Y}$ esto responde a que muchas veces el Fiscal crea imputaciones incriminatorias, sin tener como base todos los elementos objetivos del tipo penal. Pues esta omisión puede generar estados de indefensión por parte del imputado en la denominada autonomía del delito de lavado de activos en el curso del proceso penal. Surge así la inquietud: ¿La autonomía del delito de lavado de activos afecta el principio de imputación necesaria?, para ello, se ha planteado preguntas específicas para investigar, ¿Qué tipo de autonomía tiene el delito de lavado de activos?, ¿Por qué en el delito de lavado de activos es importante determinar cuál es el delito precedente?; $y$, ¿Cómo se afecta el principio de impu- tación necesaria en el delito de lavado de activos?

El objetivo general de la investigación fue determinar que la autonomía del delito de lavado de activos afecta el principio de imputación necesaria; para ello se analizó y precisó qué tipo de autonomía tiene el delito de lavado de activos; se estableció por qué en el delito de lavado de activos es importante determinar cuál es el delito precedente; y finalmente se determinó cómo se afecta el principio de imputación necesaria en el delito de lavado de activos.

\section{MATERIALES Y MÉTODO DE INVESTIGACIÓN}

Es una investigación cualitativa, en razón a que se procedió mediante la técnica de análisis de la doctrina, normas y expedientes que tengan que ver con la autonomía del delito de lavado de activos y la imputación necesaria. El tipo de investigación jurídica corresponde al jurídico dogmático, puesto que se busca dar una adecuada interpretación de la regulación que existe sobre la supuesta autonomía del delito de lavado de activos y la afectación del principio de imputación necesaria en el lavado de activos, en el proceso penal.

El ámbito de estudio se concentra en la legislación, normatividad y doctrina existente sobre la autonomía del delito de lavado de activos y la imputación necesaria, así como la doctrina jurisprudencial existente en referencia al tema de investigación. 
El universo de estudio es la legislación, normatividad y doctrina existente sobre la autonomía del delito de lavado de activos y la imputación necesaria, así como la doctrina jurisprudencial existente en referencia al tema de investigación.

La muestra de estudio para el presente trabajo de investigación se determina en la legislación existente, así como se realizará la revisión de doctrina y jurisprudencias en relación a la presente investigación.

\section{DISCUSIÓN TEÓRICA}

\subsection{Definición doctrinaria del de- lito de lavado de activos}

El delito de lavado de activos (también conocido como lavado de capitales, blanqueo de capitales u operaciones con recursos de procedencia ilícita o legitimación de capitales, reciclaje de capitales), etc., es una operación que consiste en hacer que los fondos o activos obtenidos a través de actividades ilícitas aparezcan como el fruto de actividades legales y circulen sin problema en el sistema financiero. Para que exista lavado de activos, es preciso la previa comisión de un acto delictivo de tipo grave, y la obtención de unos beneficios ilegales que quieren ser introducidos en los mercados financieros u otros sectores económicos.

La utilización de la palabra "blanqueo de capitales" sería la expresión más adecuada teniendo en cuenta que la misma es más abarcatíva, ya que el blanqueo que se realiza no solamente es de dinero sino también de otros bienes. Asimismo, restringe el concepto y considera que se trata del "proceso en virtud del cual los bienes de origen delictivo se integran en el sistema económico legal con apariencia de haber sido obtenidos de forma lícita". (Blanco Cordero, 1997, p. 101).

Constituye lavado de activos todas aquellas actividades dirigidas a ocultar la fuente o el destino del dinero o activos que se han obtenido a través de actividades ilegales. (Lamas Puccio, 2008, pp. 84-85).

Según Prado Saldarriaga (2007) "El lavado de activos es un conjunto de operaciones comerciales o financieras que procuran la incorporación al circuito económico formal de cada país, sea de modo transitorio o permanente, de los recursos, bienes y servicios que se originan o están conexos con actividades criminales" (p. 9).

Según Fabián Caparros (1998) "el blanqueo de capitales es un proceso tendente a obtener la aplicación en actividades económicas lícitas, de una masa patrimonial derivada de cualquier género de conductas ilícitas, con independencia de cuál sea la forma que esa masa adopte, mediante la progresiva concesión a la misma de una apariencia de legalidad". (p. 76).

Una denominación sugerente es la utilizada por Barral (2003), quien denomina a este tipo de hechos: "legitimación aparente del título relativo a bienes provenientes de la comisión de delitos", lo que está frase refleja es la exactitud de la naturaleza y finalidad de la acción u omisión, como tam- 
bién el objeto sobre el que recaen tales acciones, en el que se comprenden a bienes o activos en general, más allá de hablar únicamente de dinero. Se puede decir entonces que el lavado de activos o blanqueo de capitales es cualquier acción y omisión mediante el cual se pretenda otorgar apariencia de legitimidad a los bienes obtenidos por la comisión de delitos, con el fin de reintegrarlos al circuito económico legal desvinculados de su origen ilegal. (p. 39).

Gálvez Villegas (2014) menciona que "este proceso tiene por objetivo principal disimular el verdadero origen de los bienes para impedir que se los vincule con los delitos precedentes; lo esencial es hacer desaparecer ese nexo. Pero ello, no es suficiente, sino que además se requiere generar las condiciones para que tales bienes o sus sustitutos puedan ser disfrutados en paridad de condiciones con los de procedencia lícita, por lo que resulta imprescindible dotarlos de una apariencia de legitimidad que les permita circular de modo normal en el mercado" (p. 41).

Según García Cavero (2013) el delito de lavado de activos puede definirse como "proceso en virtud del cual los bienes de origen delictivo se integran en el sistema económico legal con apariencia de haber sido obtenidos de forma lícita" (p. 13).

Uno de los organismos líder en combatir esta práctica, es el Grupo de Acción Financiera Internacional (GAFI), explica, en una de las definiciones técnicas más aceptadas, que el lavado de dinero es "la conversión o transferencia de propiedad, a sabiendas de que deriva de un delito criminal, con el propósito de esconder o disfrazar su procedencia ilegal o ayudar a cualquier persona involucrada en la comisión del delito a evadir las consecuencias legales de su accionar". Es decir, el dinero obtenido de forma poco clara que, de repente, se transforma en fondos legales y preparados para ser utilizados, sin que nadie quede inculpado por ello. Pero hay muchos modos de lograrlo. Al menos así lo han entendido los criminales, que han engrasado sus mecanismos de blanqueo hábilmente para pasar desapercibidos por los organismos de control.

\subsection{Etapas y/o fases del delito de lavado de activos}

La primera fase es la de la colocación del dinero. Este ingreso de divisas en efectivo y sin título de propiedad en instituciones bancarias debe hacerse cautelosamente y sin levantar demasiadas sospechas. Introducir en una cuenta una cifra millonaria, con total seguridad pondrá en alerta a las autoridades de la (UIF.) ya que no se podrá justificar de ninguna manera el origen de estos fondos. Por eso la necesidad de utilización de testaferros se hace fundamental en esta primera fase. Generalmente, la opción más utilizada es la de dividir el dinero en varias sumas de dinero y depositarlas de diversas formas. Ya sea mediante cancelaciones de pólizas de seguro o mediante la creación de empresas offshore que aseguren el traspaso de los fondos de una manera menos obvia. 
La segunda fase es la de estratificación. Una vez que los fondos ya están inmersos en el sistema financiero, el paso siguiente es el de encubrir sus orígenes. ¿Cómo se hace? Desdoblando el dinero en multitud de transferencias de diferente índole y a diversas instituciones. De este modo, se "marea" a cualquiera que intente rastrearlo. Las divisas, de ese modo, van a parar a muchas partes del mundo, a multitud de bancos, en diferentes formatos y con nombres que no son siempre los mismos. Así se convierte en imposible seguirle la pista, ya que no se sabe a ciencia a quién de todos los testaferros inculpar.

La tercera parte del blanqueo se refiere a la integración. de esos fondos al mercado, es decir, su aparente legitimación. El paso del capital que está disperso se integra a una forma concreta. El dinero ya se encuentra transformado en diferentes formas, nombres y ubicado en muchos lugares distintos y totalmente oculto para quienes pudieran descubrir su origen. Ahora hay que hacerlo aparentar legal de una vez por todas. Y se logra haciendo más transacciones, que pueden hacerse libremente, ya que son sumas más pequeñas y mucho más fáciles de justificar ante quien lo requiera.

\subsection{Antecedentes y/o origen del delito de lavado de activos}

La decisión de la comunidad internacional en reprimir las conductas delictivas o configurativas del lavado de activos se da por aunar esfuerzos para emprender una lucha general y eficaz contra el lavado de activos de procedencia ilícita (acto criminal). Asimismo se recomienda a los diversos países implementar en sus respectivas legislaciones penales y administrativas, normas que tipifiquen el lavado de activos, para una adecuada persecución, investigación y represión de estos delitos. Así su historia legislativa se remonta a la convención de Viena de 1988 , por eso se señala que es un delito instrumental ya que se elevó a la categoría de delito para el aseguramiento de una lucha eficaz contra el tráfico ilícito de drogas y el crimen organizado, para luego expandirse a todo delito que genere dinero, bienes, efectos, y/o ganancias de origen criminal esto en la convención de Palermo del año 2000.

En nuestro país, el delito de lavado de activos actualmente está regulado en el Decreto Legislativo No 1106 denominado "Decreto Legislativo de lucha eficaz contra el lavado de activos y otros delitos relacionados a la minería ilegal y crimen organizado" que tipifica el delito como la acción de convertir, transferir, adquirir, utilizar, guardar, administrar, custodiar, recibir, ocultar, tener, transportar o trasladar dinero, bienes, efectos o ganancias cuyo origen ilícito conoce o debía presumir el autor, y cuya acción debe haberse realizado con la finalidad de evitar la identificación de su origen, su incautación o decomiso (arts. $1^{\circ}$, $2^{\circ}$ y $3^{\circ}$ ). Por lo que la estructura típica del delito de lavado de activos siempre hace referencia a un delito precedente que genera los activos objeto del delito distinto del lavado de activos, por lo que se deduce que el delito precedente 
del cual se hace mención es elemento objetivo del tipo penal.

\subsection{Efectos del delito de lavado de activos y bien jurídico protegido}

El lavado de activos afecta la integridad del sistema bancario y financiero por cuanto estos servicios dependen de la percepción de profesionalidad y standard ético que de ellas tengan sus clientes. Es importante considerar que el lavado de dinero puede potencialmente imponer costos en la economía mundial por cuanto tiene la capacidad de dañar o al menos amenazar con perjudicar las operaciones económicas de los países, corromper el sistema financiero y el sistema de administración de justicia, reduciendo la confianza del público en el sistema financiero, y por lo tanto incrementar el riesgo como la inestabilidad del sistema, y por último como consecuencia de lo expresado tiende a reducir la tasa de crecimiento de la economía.

La misión del derecho penal no es otra que la protección de "bienes jurídicos", es decir aquellos bienes vitales imprescindibles para la convivencia humana en sociedad, que por lo tanto, resultan merecedores de protección mediante el empleo del poder coactivo del Estado, mediante la imposición de la pena. Para garantizar la no lesión a la actividad económica, el Estado debe fijar qué es lo que se quiere proteger; es decir, debe determinar el bien jurídico que merece protección y/o tutela. No obstante, en la doctrina, aún no existe consenso sobre cuál es el bien jurídico a proteger en el deli- to de lavado de dinero pasando a darse varias posturas:

Postura del bien jurídico protegido "Salud Pública".- "Por un lado se habla del bien jurídico salud pública como objeto de protección. Todo ello se debe a que se relaciona directamente al lavado con el tráfico ilícito de drogas y, por ende, siendo que éste último delito afecta la salud pública, el lavado de activos lesionaría el mismo bien jurídico. Se entiende que cuando se obtienen ganancias producto de las ventas de drogas, estas ganancias tienen por finalidad ser introducidos a la economía del país para darles la apariencia de ser ganancia legal; es decir, se han lavado los activos provenientes del tráfico ilícito de drogas". (Gálvez Villegas, 2009, p. 37).

Postura del bien jurídico protegido "Administración de Justicia".- "Un sector de la doctrina penal afirma que el bien jurídico protegido en el delito de lavado de activos es la Administración de Justicia, dado que con la ocultación de los bienes se impide el cumplimiento de sus funciones, obstaculizando el descubrimiento y enjuiciamiento de los hechos". (Gómez Pavón, 1994, p. 215).

Postura del bien jurídico protegido "Orden Socioeconómico".García Cavero (2007) propone una tesis bajo criterios funcionalistas, en la que la libre y leal competencia sería la merecedora de la calificación de bien jurídico protegido con el delito de lavado de activos. En ese sentido, considera que: "el bien jurídico está constituido por las expectativas normativas 
de conducta de que el tráfico de los bienes se mueve por operaciones o transacciones realizadas realmente con las reglas del libre mercado, de manera que exista la confianza general de los agentes económicos de que los bienes no tienen una procedencia delictiva, sino que se ajustan a las reglas del tráfico jurídico patrimonial”. (pp. 488-490).

Postura del bien juridico protegido "Pluriofensivo".- La tesis de mayor aceptación en nuestro medio es la propuesta por Prado Saldarriaga, quien sostiene que con el lavado de activos se lesionan varios bienes jurídicos; es decir, asume la tesis de la pluriofensividad.

Este autor sostiene que: “(...) el lavado de dinero no está orientado hacia la afectación de un bien jurídico exclusivo y determinado, ya que dicha infracción se presenta en la realidad como un proceso delictivo que según sus manifestaciones concretas perjudica de modo simultáneo o paralelo distintos bienes jurídicos". (Prado Saldarriaga, 2007, pp. 137-138).

\subsection{La autonomía del delito de la- vado de activos, su problemá- tica con el delito precedente $y$ la imputación necesaria.}

"El tema de mayor discusión sobre el delito de lavado de activos es el relativo a su vinculación con la actividad criminal previa o lo que ha devenido en llamarse delito precedente. Pues la propia concepción del delito de lavado de activos o blanqueo de capitales denota la presencia de una ac- tividad delictiva preexistente a la cual están vinculados los activos objeto de lavado o de la cual provienen dichos activos". (Gálvez Villegas, 2014, p. 83).

Según Pariona Arana (2015), "en los últimos años se discute en nuestro país sobre la viabilidad de una "autonomía" del delito de lavado de activos que legitime una sanción penal sin la necesidad de probar el "origen ilícito" de los bienes objeto del delito. La discusión ha sido avivada con la dación del Decreto Legislativo $\mathrm{N}^{\circ}$ 1106, donde algunos han creído encontrar el respaldo legal a su propuesta. Sin embargo, como se desprende expresamente del texto legal del citado decreto, la norma peruana no regula una autonomía sustantiva, sino únicamente una autonomía procesal, por lo que para condenar legítimamente a una persona como autor del delito de lavado de activos se requiere, necesariamente, probar el origen ilícito de los bienes objeto del delito, lo cual únicamente puede hacerse probando el delito previo que originó el bien ilícito, esto siempre en el marco de un proceso judicial y mediante prueba directa o indiciaria suficiente". (p. 2)

Efectivamente, del tenor literal empleado en el Decreto Legislativo No 1106 se desprende que la acción descrita en el tipo penal consiste en dar apariencia de legalidad a bienes que provienen de la comisión de un delito previo (actividades criminales graves). Así, en los arts. $1^{\circ}, 2^{\circ}, 3^{\circ}, 4^{\circ}$ y $10^{\circ}$ de la norma se señala expresamente que los bienes objeto del delito 
tienen "origen ilícito", y que este origen ilícito presupone que los bienes provienen de "actividades criminales"; y que estas actividades criminales se circunscriben únicamente a aquellas señaladas expresamente en el art. $10^{\circ}$ de la ley: el origen ilícito de los bienes "corresponde a actividades criminales como los delitos de minería ilegal, el tráfico ilícito de drogas, el terrorismo, los delitos contra la administración pública, el secuestro, el proxenetismo, la trata de personas, el tráfico ilícito de armas, tráfico ilícito de migrantes, los delitos tributarios, la extorsión, el robo, los delitos aduaneros o cualquier otro con capacidad de generar ganancias ilegales.

Por lo que se puede deducir de la ley que para la configuración típica del delito de lavado de activos, necesariamente se tiene que vincular el delito precedente y/o preexistente que generó el dinero, bienes, efectos, y/o ganancias con el lavado de activos, en caso contrario no se podrá legítimamente imponer una pena privativa de libertad al imputado afirmando de forma general y abstracta que los bienes que posee son ilícitos y por el solo hecho de tener un desbalance patrimonial, sino que se debe probar con prueba suficiente sea directa o indiciaria que el patrimonio que posee es de origen criminal.

Asimismo, de conformidad con las garantías constitucionales, como la imputación necesaria, en materia penal se tiene que atribuir un hecho concreto, de forma precisa, detallada y circunstanciada indicando cual se- ría delito precedente que originó los bienes y dinero, etc. $Y$ de esta manera probar el origen ilícito de los bienes que el imputado tiene, admitir lo contrario sin acreditar de que delito previo concreto proviene dichos bienes afectaríamos gravemente el debido proceso y el derecho de defensa que constitucionalmente está garantizado a todo procesado.

En consecuencia, de todo lo antes señalado, se concluye que no se puede condenar a un ciudadano por la comisión del delito de lavado de activos si no se prueba, ya sea con prueba indiciaria o con prueba directa, que los bienes que posee son producto de la comisión de un determinado delito previo que provienen de la comisión de uno de los delitos previstos en el art. 10 del decreto legislativo 1106 .

La afirmación de Pariona Arana (2016) es muy acertado por lo que concuerdo con esta posición, porque como se podría condenar por la agravante del delito de lavado de activos si no se prueba con certeza de que el origen de los activos son de procedencia del narcotráfico, trata de personas, minería ilegal, etc., donde indica: "Un intento de justificación de la presunta autonomía sustantiva del delito de lavado de activos sostiene que solamente en el caso del art. $4^{\circ}$ existe la obligación de probar el delito fuente y que en todos los demás casos no existe dicha obligación. ¡Esta afirmación es incorrecta! Dicho razonamiento parte del error de considerar que solamente en los supuestos agravados contemplados en el art. $4^{\circ}$ existiría la obliga- 
ción de probar el delito fuente allí expresamente descrito; y que en los tipos básicos contemplados en los arts. $1^{\circ}$, $2^{\circ}$ y $3^{\circ}$ no existiría dicha obligación. Esto es incorrecto, pues no es el art. $4^{\circ}$, sino el art. $10^{\circ}$ el que prescribe, de manera general, para todos los casos, que el origen ilícito proviene de determinadas actividades criminales contempladas expresamente en la ley. El artículo $4^{\circ}$ sólo regula modalidades agravadas del delito de lavado de activos". (Pariona Arana, 2016, p. 28).

En ese sentido Vidal La Rosa, citando la sentencia recaída en el expediente $N^{\circ}$ 151-01 emitida por la Sala Penal Permanente de la Corte Suprema, señala que "Que el delito de blanqueo de activos no sólo descansa sobre un delito anterior (...) además exige el conocimiento del origen de los activos, aun cuando no requiere que éste sea preciso o exacto del delito ilícito de los activos, aun cuando requiere que éste sea preciso o exacto del delito previo, pues basta con la conciencia de la anormalidad de la operación a realizar y la razonable inferencia de que procede de un delito (...) el dolo exigido, por tanto, puede ser directo o eventual, en tanto es este último caso el agente considere seriamente y acepte como probable que el dinero procedía de un delito...". (Vidal La Rosa, 2014, 25).

Por ello uno de los objetivos de este trabajo fue precisar el alcance de la autonomía del delito de lavado de activos. De todo lo señalado más arriba, se concluye, que el delito de lavado de activos no tiene una autonomía sustancial pero si una autonomía procesal.
La imputación mínima o necesaria y los medios para su protección en el nuevo sistema procesal penal constituyen uno de los temas poco desarrollados en la doctrina nacional; sin embargo, la reiterada jurisprudencia del Tribunal Constitucional y de la Corte Suprema ha puesto de relieve su importancia en orden a garantizar el derecho de defensa y el deber de motivación de las resoluciones judiciales; así como, de las disposiciones y requerimientos fiscales.

"En la doctrina nacional se apunta que la imputación concreta exige casi un esfuerzo por definir ex ante los contornos de la tipicidad de la conducta del sujeto procesado, se exige una suerte de adelantamiento de la futura tipicidad; no se está pidiendo que se determine en el momento postulatorio del proceso, la responsabilidad o irresponsabilidad penal del imputado, sino el delito y los hechos por los cuales será procesado a lo largo de todo el proceso penal". (Peña Cabrera, 2012, p. 8).

"La determinación de la imputación y/o acusación cumple una doble función en el sistema penal, o en general, en el derecho sancionador. En primer lugar, fija el objeto de la investigación o del proceso penal (función de delimitación) que repercute en la precisión de los límites de la cosa juzgada o cosa decidida. En segundo lugar, la existencia de la imputación permite cumplir con la función de información al ciudadano acerca de los cargos que pesan en su contra, con el fin de que pueda diseñar de la ma- 
nera que crea conveniente su derecho de defensa. El imputado debe saber la clase y las propiedades específicas de la acción que se le atribuye haber cometido". (Castillo Alva, 2008, p. 204).

"La imputación concreta debe ser definida y configurada para posibilitar el ejercicio real del derecho de defensa materializando una resistencia idónea. Es el presupuesto necesario de la garantía principio del contradictorio, en efecto, no es posible materializar un contradictorio si no se tiene una imputación concreta. El imputado sólo puede defenderse de una imputación definida”. (Mendoza Ayma, 2011, 87).

Si bien el delito de lavado de activos tiene una estructura propia, con elementos objetivos y subjetivos propios que lo distinguen de otros delitos, desde su origen, este delito siempre ha sido un tipo penal cuya estructura típica hace referencia a un delito previo que origina los bienes ilícitos, que justamente son objeto del delito de lavado de activos. En efecto, como bien señala la Corte Suprema en su famoso Acuerdo Plenario No 3-2010/CJ-116 "el delito fuente, (...), es un elemento objetivo del tipo legal como tal debe ser abarcado por el dolo y su prueba condición asimismo de tipicidad." Por ello, la conceptualización generalizada del delito refiere que el delito de lavado de activos consiste en la acción de integrar en el sistema económico legal bienes de origen delictivo, es decir, el delito consiste en legalizar los bienes que se han obtenido producto de la comisión de un delito previo.
Según Blanco Cordero (2008), ha señalado que "ha de existir, como requisito imprescindible, un nexo entre el objeto del lavado y un delito previo. Si no está presente ese nexo o unión o si se rompe por alguna circunstancia, no existe objeto idóneo para el delito de lavado de activos. Cuando existe dicha conexión se dice que los bienes están contaminados o manchados. (p. 45).

Por su parte, Arias Torres (2010) sostiene que " (...), no se puede procesar a una persona si no se ha probado previamente el delito previo”. (p.35).

Para García Cavero (2007) “es necesario cuando menos que el delito se haya comenzado a investigar, junto con el delito de Lavado de Activos; de forma tal, que se cuenten con pruebas obtenidas con las garantías constitucionales y procesales que las hagan aptas para desvirtuar la presunción constitucional de inocencia. En caso contrario, si la investigación por el delito previo no se lleva a cabo, deberá procederse al archivamiento de la investigación por el delito de Lavado de Activos. Al respecto, concordamos con los argumentos vertidos por el autor que ha merecido la postura asumida”. (p. 505).

De esta manera, la imputación es necesaria cuando se comunica al imputado que el hecho descrito de modo suficiente por la autoridad se adecua a lo estipulado en el tipo penal objeto de incriminación y le es atribuible en calidad de autor o partícipe, fundado en elementos de convicción que así lo respalde. Al respecto, en la STC $\mathrm{N}^{\circ}$ 
03987-2010- PHC/TC se ha señalado que "En resumen el derecho a ser informado de la imputación tiene tres elementos configuradores:

1. La existencia de un hecho concreto y específico o la apariencia verosímil del mismo (STC. $\mathrm{N}^{\circ}$ 8125-2005-PHC/TC).

2. La calificación jurídica (STC. $\mathrm{N}^{\circ}$ 06079-2008-PHC/TC);

3. La existencia de evidencia o de medios de convicción (STC. $\mathrm{N}^{\circ}$ 5325-2006-PHC/TC; 95442006-PHC/TC).

En conclusión podemos afirmar de todo lo expuesto que el delito de lavado de activos supone la comisión de un delito precedente, el cual debe estar debidamente acreditado y vinculado con el lavado de activos, y, también atribuir al imputado un hecho concreto de forma precisa, detallada y circunstanciada, indicándole cual habría sido el hecho criminal generador de los activos que posee, en caso contrario se estaría afectando el principio de imputación necesaria, y vulnerando el debido proceso.

\section{RESULTADOS}

4.1. La autonomía del delito de lavado de activos afecta el principio de imputación necesaria y el principio de legalidad al no determinar cuál es el delito precedente que origina los activos ilícitos.

Según los análisis realizados respecto de la autonomía del delito de lavado de activos, podemos afirmar que, el principio de legalidad constituye uno de los cimientos sobre los que debe reposar todo Estado democrático de derecho. Los valores como la libertad y seguridad personales, son los que fundamentan este principio; por lo que la presencia del mismo en las reglas del derecho internacional público y en las del derecho penal interno, no hacen más que poner en primer orden, su importancia y su gravitación en la construcción del control penal. Está claro, pues, que este principio juega un rol elemental al fijar límites objetivos al ejercicio del poder punitivo estatal (ius puniendi); siendo uno que, por su naturaleza jurídica, cumple una función esencial y, además, establece deberes que deben ser cumplidos por los operadores del Estado, bajo el apremio de asumir responsabilidades funcionales, en caso de incumplimiento de los parámetros que introduce el principio de legalidad.

En el derecho penal, la voluntad delictiva no puede ser castigada por sí misma, por tanto lo que el sujeto activo ha querido realizar debe aparecer siempre externamente a través de una acción o de la omisión de una acción esperada; y ésta imagen exterior se traduce a través de los elementos del tipo, lo que constituye el "núcleo real y objetivo de todo delito", todo ello aunado al ámbito psíquico del autor.

En consecuencia, lo elementos objetivos del tipo penal, describen la acción, el objeto material, el resultado (en su caso), las circunstancias exter- 
nas del hecho y la persona del autor. De todos ellos resulta esencial la acción, ésta puede ser determinada de modo más detallado a través de circunstancias de distinto tipo como su relación con personas o cosas, su relación con el tiempo o el espacio, la forma y modo de ejecución, así como mediante su conexión con otras acciones.

Todo ello tiene que analizarse con los alcances de las modernas tendencias que se tiene en torno a la teoría de la imputación objetiva, en tanto que un resultado causado por una acción humana, solo puede serle imputable cuando dicha acción ha creado una puesta en peligro jurídicamente prohibida del objeto material protegido y el riesgo se ha realizado en el resultado típico. Esta imputación, puede ser negada, en tanto se suscite una ausencia de peligro jurídicamente relevante y bajo el punto de vista de la disminución del riesgo entre otras cosas eximentes que de manera específica se reconocen en el derecho penal.

En lo sustantivo, el Código Penal sobre la responsabilidad penal, precisa en su artículo VII de su Título Preliminar, que "la pena requiere de la responsabilidad penal del autor. Queda proscrita toda forma de responsabilidad objetiva"; y en cuanto al momento de la comisión del hecho delictivo, señala en su artículo $9^{\circ}$ que "el momento de la comisión de un delito es aquel en el cual el autor o participe ha actuado $u$ omitido la obligación de actuar, independientemente del momento en que el resultado se produzca"; institutos penales que deben interpretarse de la mano del significado que tiene la imputación necesaria, ampliamente desarrollada por el maestro de derecho penal Claus Roxin. Por lo que por el simple hecho de tener un desbalance patrimonial no se podría legítimamente condenar por lavado de activos a un ciudadano.

En la dogmática penal, no cabe duda que el concepto de autor está vinculado a la realización del tipo objetivo; esto es que acorde a la tendencia funcionalista del Derecho Penal, el sujeto activo debe por un lado realizar un comportamiento que satisface los componentes objetivos y subjetivos de la tipicidad (injusto penal), y por otro que sobre dicha conducta no concurra alguna causa de justificación; por tanto, cierra la posibilidad de que la configuración de la autoría se haga solo en función de la mera conducta típica pues ello conllevaría a una criminalización ilimitada de participación.

En lo procesal, el artículo IV del Título Preliminar del Código Procesal Penal, en concordancia con el artículo $65^{\circ}$ y siguientes del mismo código adjetivo penal, precisa que el Ministerio Público como titular del ejercicio público de la acción penal, tiene el deber de la carga de la prueba; no negando la posibilidad de que en su tendencia adversarial, la parte acusada y/o otras partes procesales tengan derecho de probar los hechos que conforman sus respectivas teorías del caso.

El juez es el llamado a la apreciación y valoración de la prueba y debe 
hacerlo sobre una actividad probatoria concreta, pues nadie puede ser condenado sin pruebas, y que dichas pruebas han de ser practicadas con todas y cada una de las garantías que le son propias y legalmente exigibles. También habilita que la apreciación de las pruebas debe hacerse con arreglo a las normas de la lógica, máximas de la experiencia determinadas desde parámetros objetivos y los conocimientos científicos. Todo lo cual no descarta la posibilidad de estimar ampliamente los alcances de la prueba indiciaria en caso resulte necesario.

El delito de lavado de activos tipificado en el Decreto Legislativo 1106, denominado, (Lucha eficaz contra el lavado de activos y otros delitos relacionados a la minería ilegal y crimen organizado), es un delito no convencional cuya finalidad es combatir el crimen organizado quebrantando su sistema de financiamiento económico que consiste en despojar el dinero, bienes, efectos o ganancias que tienen un origen ilícito (criminal), que hacen posible su constitución, desenvolvimiento y permanencia dentro de la sociedad cometiendo actos criminales; ya que es evidente que para el agente criminal es muy difícil disfrutar el producto de sus actos criminales esto es las ganancias.

Al respecto el Acuerdo Plenario $\mathrm{N}^{\circ} 03-2010 / \mathrm{CJ}-116$ de fecha 16 de noviembre del 2010, precisa en su fundamento $7^{\circ}$ : "Se identifica como lavado de activos a todo acto o procedimiento realizado para dar una apariencia de legitimidad a los bienes y capitales que tienen un origen ilícito. El delito de lavado de activos es un delito no convencional y constituye en la actualidad un notorio exponente de la moderna criminalidad organizada (...)".

"En este delito el bien jurídico tutelado son las funciones, la estabilidad, o el régimen regulador de la actividad económica. El lavado de activos se convierte hoy en un delito que desestabiliza el orden económico y perjudica de manera muy grave el tráfico comercial, contaminando el mercado en bienes y recursos de origen ilícito. Cabe decir que la tipificación del delito de lavado de activos encuentra su justificación en la necesidad de proteger penalmente determinadas manifestaciones concretas propias del funcionamiento de las estructuras económicas". (Prado Saldarriaga, 2013, p. 202).

Sobre los aspectos relevantes en torno a su tipicidad objetiva, y tomando en cuenta la circunstancia agravante, necesariamente se tiene la necesidad de establecer que el dinero provenga del tráfico ilícito de drogas (en caso concreto), cuyos beneficios pasen y/o traten de integrarse en el ámbito de las relaciones jurídicas lícitas, distorsionando así las reglas básicas que rigen el desarrollo del mercado de capitales y bienes.

Se califica como un delito pluriofensivo (afectación de varios bienes jurídicos) y tiene carácter no convencional; traducido en fases comitivas como son la colocación - intercalación - e integración. El modus operandi, precisa que la autoría en el la- 
vado de activos no exige cualificación especial. Por tanto se considera como un típico delito común que puede ser realizado por cualquier persona a título de autor o partícipe. En tanto que el sujeto pasivo siempre será el Estado.

En relación a la consumación del delito de lavado de activos, el Acuerdo Plenario 03-2010/CJ-116 emitido por la Corte Suprema de la República, señala que se trata de un delito de resultado y corroborando con el VI peno jurisdiccional sobro dicha materia (publicado por el instituto de ciencia procesal penal), las diferentes modalidades delictivas de lavado de activos tienen un elemento que sin duda tiene especial interés a la hora de poder establecer un criterio que permita definir el momento de consumación de cada una de las conductas descritas; dicho elemento versa sobre la dificultad que genera el sujeto activo en torno a la identificación de su origen, su incautación o decomiso.

En cuanto a su tipicidad subjetiva, estos delitos se cometen a título de dolo (que contempla el dolo eventual); ligado en estricto a que los actos a realizar por el agente del delito vayan encaminados a dificultar el que se conozca el origen delictivo de los bienes o ganancias, por un lado, o su incautación o decomiso, por otro, lo que de igual manera vincula tales viene con la fuente ilícita que ha permitido su obtención, y sólo cabe entender dicha conducta sobre la base del conocimiento expreso y directo de su origen, de ahí que la figura del lavado de activos tiene como presupuesto básico para su ejecución, desde el punto de vista del grado de conocimiento con el que actúa el sujeto activo, el saber o presumir que el objeto material del delito tiene origen ilegal (criminal).

En un caso concreto, acorde a la naturaleza del tipo penal de lavado de activos, el comportamiento del o los sujetos exige que hayan proporcionado una contribución esencial y que su aporte implique un aporte imprescindible para que se consigan los resultados descritos en la norma; todo ello en cuanto exige la teoría del dominio del hecho, ejemplo: "si los hechos imputados solo aluden a las circunstancias concomitantes de una intervención del vehículo en el que transportaba el acusado llevando el dinero por la suma de \$. 10,500.00 dólares americanos; y que uno de los fajos que es sometido a la prueba de campo arrojó positivo para adherencias de alcaloide de cocaína. Nótese que la imputación fáctica, no precisa cuál era la finalidad que tenía el encausado; por tanto, en puridad, el solo hecho vinculado al descubrimiento de dinero y presumiblemente que dicho dinero provenga del tráfico de drogas, no basta para contemplar que concurran todos los elementos configurativos del tipo penal. Por tanto, el solo hecho de llevar dinero, no puede conllevar a establecer que ese comportamiento implique una contribución decidida al lavado de activos".

Una opción político criminal para lograr la persecución e investigación del delito de lavado de activos en los casos que el hecho previo no se 
encuentre acreditado suficientemente y que el autor del delito de lavado de activos no es el autor del delito previo, es manteniendo la autonomía procesal del delito de lavado de activos, lo que ha puesto en evidencia el aumento de inicio de procesos penales por lavado de activos sustentado el hechos previos hipotéticos, basados en especulaciones o en el mejor de los casos en indiciarios, que a lo largo de la investigación van acreditándose o desvirtuándose.

La configuración del delito previo en aquellos casos más complejos y problemáticos donde el autor del delito previo no es el autor del delito de lavado, y donde no exista resolución judicial firme a través de la cual se pruebe o acredite el hecho ilícito o delito previo, desde mi punto de vista sí es posible que en el mismo proceso de lavado de activos se realice actividad probatoria con el objeto de acreditar o desvirtuar el hecho ilícito, en la medida que la existencia de un delito previo o un hecho ilícito constituye un elemento objetivo del tipo penal de lavado de activos, con lo cual nos inclinamos en defender que no es posible sostener la autonomía sustancial del delito de lavado de activos, en la medida que ya sea intra o extra proceso debe acreditarse el delito previo para su total configuración.

La mayoría de las absoluciones que se dan en los procesos seguidos por lavado de activos, se basan en no haberse podido acreditar el hecho ilícito, la conexión del hecho ilícito con los activos y/o el conocimiento del autor sobre la existencia del hecho ilí- cito. Ello se debe a que el delito de lavado de activos exige como elemento objetivo del tipo penal que exista un hecho ilícito, y si no es posible acreditar ese elemento objetivo, de ninguna forma podrá acreditarse el resto de elementos que exige el tipo penal, por tanto no existe autonomía sustancial entre el delito de lavado de activos y el delito previo mientras se encuentre establecido como un elemento objetivo del tipo de lavado.

\section{CONCLUSIONES}

Después de haber analizado e investigado sobre la incidencia práctica del delito de lavado de activos en nuestro País, específicamente en el Distrito Judicial de Puno, analizando el delito en estudio sobre la controversia que existe en cuanto a la determinación de la autonomía o no del delito de lavado de activos. Se determinó verificando adecuadamente la doctrina y la norma que al considerar al lavado de activos como un delito autónomo se afecta directamente el principio de imputación necesaria porque para acusar y sentenciar por lavado de activos se tiene que configurar todos los elementos objetivos y subjetivos del tipo penal para efectuar una adecuada imputación, caso contrario se estaría dejando en estado de indefensión al imputado. Sin embargo advertimos que estamos ante la presencia de un delito complejo, que necesita un tratamiento sistemático.

En relación a la autonomía del delito de lavado de activos se precisa que tiene una autonomía procesal, 
dado que para aperturar la investigación no es necesario que el delito precedente este probado con sentencia condenatoria firme, mas no una autonomía sustantiva dado que dado que uno de los elementos objetivos del tipo penal es el delito precedente, $y$ sin ese elemento no se podría efectuar una imputación necesaria el cual constituye una garantía constitucional a todo procesado.

Se estableció que es importante determinar cuál es el delito precedente en el de lavado de activos porque esta constituye un elemento objetivo del tipo penal, y porque no se podría condenar por la agravante si no se determina cual es el delito que origino dichos activos; por lo que sin la presencia de este elemento no se configuraría la tipicidad del delito imputado. $\mathrm{Y}$ no es posible defender una autonomía sustancial del delito de lavado de activos con respecto el hecho ilícito previo.

En la ley penal especial se considera que el lavado de activos cuenta con una autonomía procesal y sustancial, analizando dogmáticamente consideramos que esta definición legal carece de fundamentos doctrinarios uniformes y en ese sentido se considera que afecta el principio de imputación necesaria al no establecer con claridad la conexión entre delito de lavado de activos y el delito precedente. Se determinó que para realizar una imputación necesaria por el delito de lavado de activos es necesario y un requisito esencial el delito precedente para la configuración de este delito, en este orden de ideas se establece que se afecta el principio de imputación necesaria cuando se sostiene la autonomía del delito de lavado de activos.

\section{SUGERENCIAS}

Tomando en consideración la autonomía del delito de lavado de activos, y, que el principio de legalidad constituye uno de los cimientos sobre los que debe reposar todo Estado democrático de derecho como también el principio de imputación necesaria que garantiza la defensa eficaz y oportuna, como expresión del debido proceso se sugiere en aras de no generar confusión e interpretación equivocas que: La Corte Suprema de la Republica debiera celebrar un acuerdo plenario donde se emita un pronunciamiento uniforme y contundente acerca de la autonomía del delito de lavado de activos, y de esta manera no generar inseguridad jurídica.

\section{BIBLIOGRAFÍA}

1. Bajo Fernández, Miguel, \& Suarez Gonzáles, Carlos, 2da Edición (1993). Manual de Derecho Penal. Delitos Patrimoniales y Económicos. Madrid, España: Ceura.

2. Barral, Jorge Enrique, (2003). Legitimación de bienes provenientes de la comisión de delitos. Buenos Aires: Ad - Hoc.

3. Bernal Cavero, Jorge Antonio, (2007). El Lavado de Activos en la Legislación Peruana: Aspectos Sustantivos, Procesales y Conexos. 
Lima: Editorial San Marcos.

4. Blanco Cordero, Isidoro, (1997). El delito de blanqueo de capitales. Madrid, España: Arazandi.

5. Castillo Alva, José Luis, (2008). "El Derecho a ser Informado de la Imputación" Temas Penales en la Jurisprudencia del Tribunal Constitucional. Lima: Fondo Editorial PUCP.

6. Castillo Alva, José Luis, (2009). La necesidad de determinación del "delito previo" en el delito de lavado de activos. Lima: Gaceta Jurídica.

7. Fabián Caparrós, Eduardo A, (1998). El Delito de Blanqueo de Capitales. Madrid: Colex.

8. Gálvez Villegas, Tomás Aladino. (2014). El Delito de Lavado de Activos Criterios Sustantivos y Procesales Análisis del Decreto Legislativo 1106. Lima: Instituto Pacifico SAC.

9. Gálvez Villegas, Tomás Aladino, 2da Edición (2009). El delito de lavado de activos. Criterios Sustantivos y procesales, análisis de la Ley 27765. Lima: Editorial Jurista.

10. García Cavero, Percy, (2007). Derecho Penal Económico. Parte Especial. Tomo I. Lima: Grijley.

11. García Cavero, Percy, (2007). Derecho Penal Económico. Parte Especial Tomo II. Lima: Grijley.

12. Reátegui Sánchez, James, (2011). Más sobre el principio de imputación necesaria. Lima: Gaceta Penal \& Procesal Penal.

13. Lamas Puccio, Luis, (2008). Inteligencia Financiera y Operaciones Sospechosas. Lima: Gaceta Jurídica.

14. Lamas Puccio, Luis, (2000). Transacciones financieras sospechosas. Lima: Ediciones Jurídicas.

15. Mendoza Ayma, Francisco Celis, (2012). La necesidad de una imputación concreta en el desarrollo del proceso penal cognitivo. Arequipa: San Bernardo.

16. Pariona Arana, Raúl, (2016). ¿Puede condenarse a una persona por lavado de activos sin que se pruebe el delito previo? Lima: La Ley el Angulo Legal de la Noticia.

17. Peña Cabrera Freyre, Alonso Raúl, (2014) El principio de imputación necesaria: una garantía procesal y sustantiva a la vez, derivada del diseño de un sistema penal democrático y garantista. Lima:http://www.mpfn.gob.pe/ escuela/contenido/actividades/ docs/2608_02principio_de_imputacion_necesaria.pdf

18. Prado Saldarriaga, Víctor Roberto, (2013). Criminalidad Organizada y Lavado de Activos. Lima: Idemsa.

19. Prado Saldarriaga, Víctor Roberto. (2007). Lavado de Activos y Financiamiento del Terrorismo. Lima: Grijley. 
